\title{
Outcomes of Surgical Patch Angioplasty of the Coronary Artery for Diffuse Coronary Artery Disease
}

\author{
Dong Li ${ }^{1}$, MD; Pengfei Guo ${ }^{1}$, MS; Lei Chen ${ }^{1}$, MS; Yang Wu${ }^{1}$, MD; Gang Wang ${ }^{1}$, MD; Cangsong Xiao ${ }^{1}$, MD
}

DOI: $10.21470 / 1678-9741-2019-0390$

\section{Abstract}

Introduction: Diffuse coronary artery disease (CAD) has a poor prognosis and many patients are ineligible for conventional coronary artery bypass grafting (CABG). This study evaluated the 12-month outcomes of coronary artery reconstruction and surgical patch angioplasty of the coronary artery for diffuse CAD.

Methods: A retrospective cohort study of patients who underwent CABG with surgical patch angioplasty of the coronary artery (reconstruction group) or standard CABG alone (standard group) at the Cardiovascular Surgery Department of the local Hospital between January 2014 and January 2016. Follow-up was censored at 12 months after surgery.

Results: Cardiopulmonary bypass and aortic cross-clamping durations were longer in the reconstruction group $(n=32)$ than in the standard group $(n=125)(P<0.05)$. There were no differences in graft blood flow and postoperative levels of cardiac markers between the two groups ( $P>0.05)$. In the reconstruction group, one patient died; a vein graft showed occlusion. In the standard group, two patients died; one left internal mammary artery graft and three vein grafts showed occlusion. There were no significant differences in mortality, major adverse cardiovascular and cerebrovascular events, and patency between the two groups $(P>0.05)$.

Conclusion: Coronary artery reconstruction and surgical patch angioplasty of the coronary artery can be performed for diffuse CAD. Patient outcomes were not significantly different from those of patients who underwent standard CABG.

Keywords: Coronary Artery Disease. Mammary Arteries. Cardiopulmonary Bypass. Retrospective Studies. Follow-Up Studies. Constriction. Coronary Artery Bypass. Angioplasty. Myocardial Revascularization. Prognosis.

\begin{tabular}{llll}
\hline \multicolumn{2}{l}{ Abbreviations, acronyms \& symbols } & & \\
\hline CABG & $=$ Coronary artery bypass grafting & LAD & $=$ Left anterior descending artery \\
CAD & $=$ Coronary artery disease & LIMA & $=$ Left internal mammary artery \\
CK-MB & $=$ Creatine kinase MB & LMCA & $=$ Left main coronary artery \\
CPB & $=$ Cardiopulmonary bypass & MACCE & $=$ Major adverse cardiovascular and cerebrovascular \\
CTA & $=$ Computed tomography angiography & & events \\
CT & $=$ Computed tomography & MI & $=$ Myocardial infarction \\
GSV & $=$ Great saphenous vein & PCI & $=$ Percutaneous coronary intervention \\
HTK & $=$ Histidine-tryptophan-ketoglutarate & SVG & $=$ Saphenous vein graft \\
ICU & $=$ Intensive care unit & TTFM & $=$ Transit-time flow measurement
\end{tabular}

\section{INTRODUCTION}

Diffuse coronary artery disease (CAD) is generally considered in the presence of a narrowing $\geq 70 \%$ ) of a coronary artery $\geq 20$ $\mathrm{mm}$ or in the presence of multiple stenoses encompassing the whole length of the coronary artery ${ }^{[1,2]}$. Nevertheless, diffuse CAD can lead to severe myocardial ischemia and thereby angina,

'Department of Cardiovascular Surgery, Medical School of Chinese PLA, Beijing, China.

This study was carried out at the Department of Cardiovascular Surgery, Medical School of Chinese PLA, Beijing, China. myocardial infarction (MI), and even heart failure, especially when the left anterior descending artery (LAD) is extensively involved ${ }^{[1,3-5]}$. The prognosis of diffuse CAD after stenting or coronary artery bypass grafting (CABG) is unknown.

One possible treatment for coronary artery stenosis is CABG, but many patients with diffuse CAD are ineligible to traditional

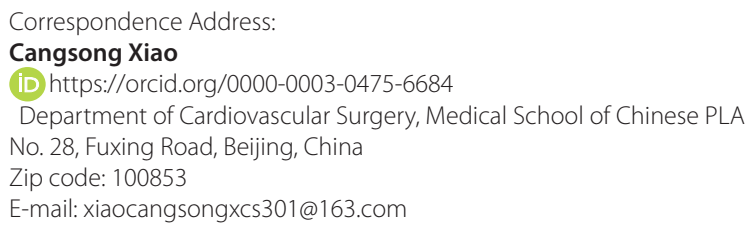


CABG techniques ${ }^{[1,6-10]}$ or CABG does not achieve the desired results ${ }^{[11,12]}$. This is because the diffuse atherosclerotic lesions render the artery unsuitable for distal grafting ${ }^{[13]}$.

A number of surgical techniques have been proposed ${ }^{[13]}$. Coronary arteries with diffuse stenosis can be effectively widened and reconstructed by CABG using patches taken from the left internal mammary artery (LIMA) or great saphenous vein (GSV) in situ, achieving good outcomes ${ }^{[14]}$. Coronary artery reconstruction and surgical patch angioplasty of the coronary artery have been described mainly for the treatment of isolated ostial stenosis of the left main coronary artery (LMCA), which is a rare condition ${ }^{[15]}$. This approach has also been described as a rescue surgery after percutaneous coronary intervention ( $\mathrm{PCI}$ ) complications ${ }^{[16]}$ and for the treatment of rare congenital heart conditions $^{[17]}$. Nevertheless, considering the relative novelty of the technique and the low prevalence of diffuse CAD, data regarding the outcomes of this surgery for diffuse CAD are still lacking.

Therefore, this study aimed to evaluate the outcomes of coronary artery reconstruction and surgical patch angioplasty of the coronary artery for diffuse CAD.

\section{METHODS}

\section{Study Design and Patients}

This is a retrospective cohort study of patients who underwent coronary artery reconstruction and surgical patch angioplasty of the coronary artery (reconstruction group) or standard CABG alone (standard group) at the Cardiovascular Surgery Department of the Hospital between January 2014 and January 2016.

The surgical indications were: 1) stable angina pectoris: conservative treatment was ineffective; coronary artery angiography showed that the coronary artery trunk or the stenosis of proximal end of anterior descending branch/circumflex artery was $>70 \%$, patients with lesions in three branches of the coronary artery, especially patients with low left ventricular ejection fraction of cardiac function; 2) unstable angina: typical angina that affects daily life and work, and conservative treatment was ineffective; coronary artery angiography showed that the coronary artery trunk or the stenosis of proximal end of anterior descending branch/circumflex artery was $>70 \%$; 3) severe coronary stenosis: three major branches of the coronary artery (anterior descending branch, circumflex artery, right coronary artery) had severe stenosis (>75\%); and 4) failure of interventional treatment.

Patients who underwent CABG surgery by the same surgeon for CAD during the study period were included. Exclusion criteria were: 1) other cardiac surgery during $(A B G ; 2)$ abnormal preoperative coagulation function or platelet count; or 3) preoperative cardiac dysfunction (left ventricular long diameter $>60 \mathrm{~mm}$ or ejection fraction $<50 \%$ ). Data were extracted from the medical records.

This study was approved by the ethics committee of the local hospital. The need for individual consent was waived by the committee because of the retrospective nature of the study.

\section{Surgical Procedures}

Coronary artery reconstruction and surgical patch angioplasty of the coronary artery were performed in patients with diffuse stenosis of the target vessels. Conventional CABG was performed in patients with conventional non-diffuse stenosis.

All surgeries were performed under general anesthesia and cardiopulmonary bypass (CPB) by the same three surgeons, including a chief surgeon, an attending surgeon, and a surgeon. Sternotomy and establishment of CPB were routinely performed.

In the reconstruction group, patient-specific conditions were determined by angiography performed by experienced technicians (Innova 3100-IQ, GE Healthcare, Waukesha, WI, USA; contrast: Optiray 320, Mallinckrodt Pharmaceuticals, Stainesupon-Thames, UK). Then, surgery was performed according to the angiography results: 1) an anastomosis was established between the LIMA patch and LAD; 2) LAD was reconstructed with a saphenous vein graft (SVG) patch and anastomosis of LIMA to the SVG patch; or 3) target arteries with diffuse disease, except for LAD, were reconstructed using SVG. In each patient, the incision started from the middle portion of the LAD and continued towards its distal and proximal ends. At the distal end of $L A D$, the incision was terminated in a proper position in the coronary artery lumen; at the proximal end, a major stenosis was left intact in order to avoid competitive flow in the postoperative period. For each of the patients undergoing in situ LIMA patch reconstruction, the distal ventral portion of LIMA was cut longitudinally to obtain an arterial patch whose length fit the incision made in LAD. Then the patch was continuously sutured to LAD using 7/0 Prolene suture for reconstruction (Figure 1). For each of the patients undergoing SVG reconstruction, SVG was incised longitudinally to obtain an SVG with proper length and

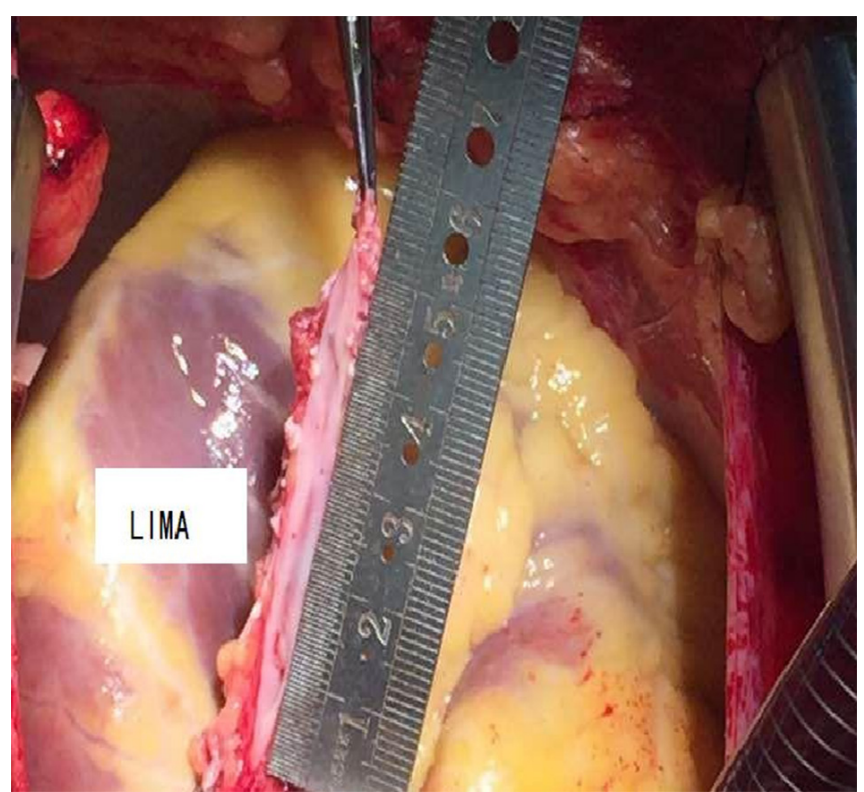

Fig. 1 - Onlay reconstruction and revascularization of the left anterior descending artery (LAD) with in situ pedicled left internal mammary artery (LIMA). 
width and then SVG was used to reconstruct the LAD. An end-toside anastomosis was created between LIMA and SVG (Figure 2). The suturing ensured that atherosclerotic plaques were isolated from the coronary artery lumen after angioplasty.

For the patients who underwent standard CABG, LIMA was anastomosed to LAD, and SVG was anastomosed with other diseased target arteries.

For patients with diffuse disease of coronary arteries except $L A D$, the distal stenoses to be bypassed were cut, with the incisions extending to normal positions in arterial walls at both the proximal and distal ends (both incisions' ends were usually about $2 \mathrm{~mm}$ beyond the boundaries of the stenoses). The incision in each SVG was prolonged to fit the length of the target artery. SVG and target artery were continuously anastomosed by endto-side anastomosis using 7/0 Prolene suture. After angioplasty, the atherosclerotic plaques were separated from the lumen of the arteries.

All patients included in this study did not undergo coronary endarterectomy. After the end of CPB, a transit-time flow measurement (TTFM) was used to measure and record blood flow in the grafts and ensure it was satisfactory before closing the chest.

The patients routinely received $75 \mathrm{mg}$ clopidogrel and 100 mg oral enteric-coated aspirin immediately after tracheal tube removal on the morning of the $1^{\text {st }}$ operative day, for 1 year. CK-

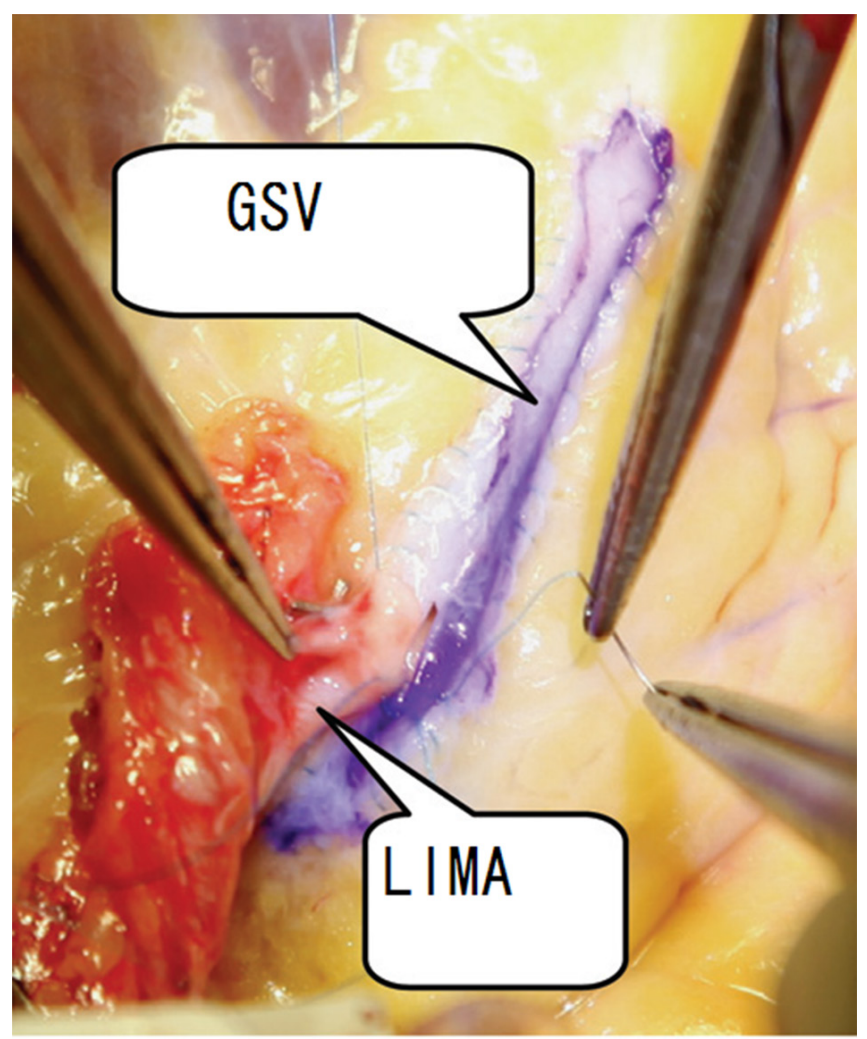

Fig. 2 - A great saphenous vein (SVG) was used for left anterior descending artery ( $L A D)$ onlay reconstruction. The left internal mammary artery (LIMA) was anastomosed to the GSV in an end-toside fashion.
MB and troponin T (COADS-8000, Roche, Germany) levels in peripheral blood were routinely monitored on postoperative days $1-3$.

\section{Follow-Up}

Patients were routinely followed at 6 and 12 months, and then annually. Coronary artery CT angiography was performed using 64-MSCT (SOMATOM Sensation Cardiac 64, Siemens, Erlangen, Germany) to verify graft patency at 6 months. Mortality, major adverse cardiovascular and cerebrovascular events (MACCE) (including death, non-fatal myocardial infarction, revascularization, stroke, and cerebral hemorrhage), graft patency, and complications were extracted from medical records.

\section{Statistical Analysis}

Statistical analysis was performed using SPSS 19.0 (IBM, Armonk, NY, USA). Continuous data are presented as mean \pm standard deviation and were analyzed using the Student's t-test. Categorical data are presented as percentage and were analyzed by chi-square test or Fisher's exact test, as appropriate. Two-sided $P$-values $<0.05$ were considered statistically significant.

\section{RESULTS}

\section{Patient Characteristics}

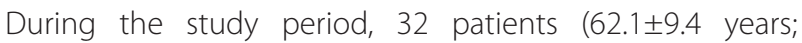
$71.9 \%$ male; $23.5 \pm 3.8 \mathrm{~kg} / \mathrm{m}^{2}$ ) underwent coronary artery reconstruction and surgical patch angioplasty of the coronary artery (reconstruction group) and 128 patients (63.7 \pm 11.4 years; $83.6 \%$ male; $23.2 \pm 3.6 \mathrm{~kg} / \mathrm{m}^{2}$ ) underwent CABG alone (standard group). Table 1 presents the preoperative data of the patients. There were no significant differences between the two groups in terms of age, gender, angina, number of diseased arteries, left ventricular systolic function, myocardial infarction (MI), hypertension, diabetes, cerebrovascular diseases, and chronic renal insufficiency (all $P>0.05$ ).

\section{Intraoperative and Postoperative Data}

In the reconstruction group, the bypasses were $3.5 \pm 0.9 \mathrm{~cm}$ in length. An anastomosis was established between the LIMA patch and $L A D$ in 18 cases, and 4 cases underwent $L A D$ reconstruction with SVG patch and anastomosis of LIMA to SVG patch. The 10 patients with target arteries other than LAD underwent reconstruction using the SVG surgical technique; there were one case of stenotic diagonal branch artery, five of diseased posterior descending artery, two of diseased posterior branch of left ventricle, and two of stenotic obtuse marginal branch.

After surgery, patients had no angina and were discharged from the hospital after recovery. Complications such as perioperative $\mathrm{MI}$, low cardiac output, malignant ventricular arrhythmias, reoperation for hemostasis, stroke and renal insufficiency did not occur. Table 2 shows the intraoperative and postoperative data of both groups. The proportion of patients with two-vessel disease was higher in the reconstruction group 
Table 1. Comparison of preoperative data.

\begin{tabular}{|c|c|c|c|}
\hline & $\begin{array}{l}\text { Reconstruction } \\
(n=32)\end{array}$ & $\begin{array}{l}\text { Standard } \\
(n=128)\end{array}$ & $P$-value \\
\hline Age (years) & $62.1 \pm 9.4$ & $63.7 \pm 11.4$ & 0.83 \\
\hline Gender, male, n (\%) & $23(71.9)$ & $107(83.6)$ & 0.21 \\
\hline BMI $\left(\mathrm{kg} / \mathrm{m}^{2}\right)$ & $23.5 \pm 3.8$ & $23.2 \pm 3.6$ & 0.66 \\
\hline Smoking history, n (\%) & $19(59.4)$ & $73(57.0)$ & 0.84 \\
\hline $\mathrm{Ml}, \mathrm{n}(\%)$ & $9(28.1)$ & $36(28.1)$ & 0.92 \\
\hline Left ventricular ejection fraction (\%) & $59.5 \pm 11.5$ & $62.1 \pm 9.9$ & 0.48 \\
\hline \multicolumn{4}{|l|}{ Number of diseased arteries, n (\%) } \\
\hline 2 & $3(9.4)$ & $13(10.2)$ & \\
\hline 3 & $29(90.6)$ & $115(89.8)$ & \\
\hline Diabetes, n (\%) & $10(31.3)$ & $48(37.5)$ & 0.76 \\
\hline Hypertension, n (\%) & $18(26.3)$ & $75(58.6)$ & 0.68 \\
\hline Peripheral vascular diseases, n (\%) & $3(9.4)$ & $5(3.9)$ & 0.32 \\
\hline Cerebrovascular diseases, n (\%) & $4(12.5)$ & $15(11.7)$ & 0.91 \\
\hline Chronic renal insufficiency, n (\%) & $1(3.1)$ & $3(3.9)$ & $>0.99$ \\
\hline
\end{tabular}

$\mathrm{BMI}=$ body mass index; $\mathrm{Ml}=$ myocardial infarction

Table 2. Intraoperative and postoperative data.

\begin{tabular}{|c|c|c|c|}
\hline & $\begin{array}{l}\text { Reconstruction } \\
\qquad(n=32)\end{array}$ & $\begin{array}{l}\text { Standard } \\
(n=128)\end{array}$ & $P$-value \\
\hline Number of bypassed arteries, n (\%) & & & 0.01 \\
\hline 2 & $10(31.3)$ & $14(10.9)$ & \\
\hline 3 & $14(43.8)$ & $76(59.4)$ & \\
\hline 4 & $8(25.0)$ & $38(29.7)$ & \\
\hline Blood flow in LAD (ml/min) & $35.3 \pm 8.7$ & $28 \pm 13.6$ & 0.51 \\
\hline Blood flow in SVG (ml/min) & $39.1 \pm 18.6$ & $36.1 \pm 14.8$ & 0.96 \\
\hline Cardiopulmonary bypass time (min) & $116.5 \pm 21.3$ & $97.2 \pm 29.6$ & 0.04 \\
\hline Aortic cross-clamping time (min) & $95.3 \pm 21.5$ & $66.9 \pm 20.7$ & $<0.01$ \\
\hline Ventilator support time (h) & $18.8 \pm 9.1$ & $18.7 \pm 11.3$ & 0.74 \\
\hline ICU length of stay (d) & $3.1 \pm 1.5$ & $3.3 \pm 1.3$ & 0.09 \\
\hline Postoperative atrial fibrillation, n (\%) & $3(9.4)$ & $15(11.7)$ & 0.68 \\
\hline Postoperative MI, n (\%) & 0 & $2(1.6)$ & 0.75 \\
\hline Postoperative renal insufficiency, n (\%) & $1(3.1)$ & $2(1.6)$ & 0.79 \\
\hline Postoperative stroke, n (\%) & 0 & $2(1.6)$ & 0.88 \\
\hline Ventricular arrhythmias, n (\%) & 0 & $1(0.8)$ & 0.93 \\
\hline
\end{tabular}

$I C U=$ intensive care unit; $L A D=$ left anterior descending artery; $M \mid=$ myocardial infarction; SVG=saphenous vein graft

than in the standard group (31.3\% vs. $10.9 \%, P=0.01)$. There were no significant differences in blood flow (LAD and SVG), duration of ventilator use, intensive care unit (ICU) stay, postoperative atrial fibrillation, postoperative $\mathrm{MI}$, postoperative renal failure, postoperative stroke, ventricular arrhythmias, postoperative mortality rate and complications between the two groups (both $P>0.05)$. The duration of CPB (116.5 \pm 21.3 vs. 97.2 \pm 29.6 min, $P=0.04)$ and aortic cross-clamping $(95.3 \pm 21.5$ vs. $66.9 \pm 20.7 \mathrm{~min}, P<0.01)$ in 
the reconstruction group were significantly longer than in the standard group. There were no significant differences in CK-MB and troponin T levels on $3^{\text {rd }}$ postoperative day (all $P>0.05$ ) (Table 3 ).

\section{Follow-Up}

In the reconstruction group, all 32 patients were followed (100\%). During follow-up, one patient died from cerebral hemorrhage. All 31 remaining patients underwent coronary computed tomography angiography (CTA) follow-up. All LIMA grafts were patent, and one vein graft showed occlusion. In the standard group, 125 patients were followed (98\%). Two patients died, one from heart failure combined with pulmonary infection and the other from recurrent MI. Coronary CTA follow-up was performed in 120 patients. One LIMA graft and three vein grafts showed occlusion. There were no significant differences in mortality rate, occurrence of MACCE (death, non-fatal myocardial infarction, revascularization, stroke, and cerebral hemorrhage), and patency rate between the two groups (Table 4).

\section{DISCUSSION}

This study suggests that coronary artery reconstruction and surgical patch angioplasty of the coronary artery can be performed for diffuse CAD. Patient outcomes were not significantly different from those of patients who underwent standard CABG.

Complete revascularization is commonly accepted in CABG. If a coronary artery has a long segment of stenosis, simple CABG is not effective in unblocking all diseased vessels. For patients with diffuse coronary artery stenosis, incomplete revascularization is an independent risk factor that influences prognosis ${ }^{[1,18]}$. For patients with diffuse disease in LAD and its interventricular branch, in particular, revascularization cannot achieve the desired results and is considered as a major risk factor for postoperative MACCE ${ }^{[19]}$. Diffuse coronary artery stenosis can not only complicate surgical procedures, but also reduce long-term graft patency ${ }^{[20]}$. Nevertheless, patients with diffuse CAD will still have a worse prognosis if they do not receive $C A B G$, despite the difficulty and high risk in performing CABG on them ${ }^{[1]}$. A followup survey of patients who were denied CABG because of diffuse CAD found that $39.2 \%$ of these patients died of cardiac causes, $37.2 \%$ died of acute $\mathrm{MI}$, and $5.8 \%$ developed congestive heart failure ${ }^{[21]}$.

Coronary artery reconstruction is one of the effective methods for treating severe diffuse $\mathrm{CAD}^{[22]}$. Through a comparison of coronary artery reconstruction with endarterectomy, Fukui et

Table 3. Postoperative levels of myocardial enzymes.

\begin{tabular}{|c|c|c|c|}
\hline & $\begin{array}{l}\text { Reconstruction } \\
(n=32)\end{array}$ & $\begin{array}{c}\text { Standard } \\
(n=128)\end{array}$ & $P$-value \\
\hline \multicolumn{4}{|l|}{ Troponin T (ng/ml) } \\
\hline $1^{\text {st }}$ postoperative day & $0.3 \pm 0.1$ & $0.3 \pm 0.2$ & 0.58 \\
\hline $2^{\text {nd }}$ postoperative day & $0.3 \pm 0.2$ & $0.3 \pm 0.3$ & 0.89 \\
\hline $3^{\text {rd }}$ postoperative day & $0.2 \pm 0.1$ & $0.3 \pm 0.1$ & 0.67 \\
\hline \multicolumn{4}{|l|}{ CK-MB (ng/ml) } \\
\hline $1^{\text {st }}$ postoperative day & $12.0 \pm 5.4$ & $11.3 \pm 6.4$ & 0.59 \\
\hline $2^{\text {nd }}$ postoperative day & $7.0 \pm 0.8$ & $7.7 \pm 0.5$ & 0.73 \\
\hline $3^{\text {rd }}$ postoperative day & $2.4 \pm 0.8$ & $3.3 \pm 1.7$ & 0.55 \\
\hline
\end{tabular}

$\mathrm{CK}-\mathrm{MB}=$ creatine kinase $\mathrm{MB}$

Table 4. Follow-up.

\begin{tabular}{l|c|c|c}
\hline & $\begin{array}{c}\text { Reconstruction } \\
(\mathbf{n = 3 2 )}\end{array}$ & $\begin{array}{c}\text { Standard } \\
(\mathbf{n = 1 2 5})\end{array}$ & $\mathbf{P}$-value \\
\hline Mortality rate, $\mathrm{n}(\%)$ & $1(3.1)$ & $7(5.6)$ & 0.87 \\
\hline Incidence of MACCE, $\mathrm{n}(\%)$ & $2(6.3)$ & $119(99.2)$ & 0.77 \\
\hline LIMA graft patency rate, $\mathrm{n}(\%)$ & $32(100.0)$ & $118(98.3)^{* *}$ & 0.48 \\
\hline Vein graft patency rate, $\mathrm{n}(\%)$ & $31(96.9)^{*}$ & 0.56 \\
\hline
\end{tabular}

LIMA=left internal mammary artery; MACCE=major adverse cardiovascular and cerebrovascular events

*A patient can undergo bypass with multiple venous bridges; 32 patients had a total of 62 venous bridges; one failed; the patency rate was 61/62 (98.4\%).

**A patient can undergo bypass with multiple venous bridges; 120 patients had a total of 264 venous bridges; three failed; the patency rate was 261/264 (98.7\%). 
al. ${ }^{[11]}$ found that a higher patency rate can be achieved using LIMA patch reconstruction. A 3-year follow-up survey showed that the patency rate of artery in the reconstruction group reached $97.6 \%$, compared to $89.7 \%$ in the endarterectomy group. A study by Ogus et al. ${ }^{[23]}$ reported good short- and longterm results of LIMA patch reconstruction; the mortality rate in the early postoperative period was 1.9\%; the 3-year, 5-year, and 7 -year survival rates were $93.8 \%, 89.6 \%$, and $85.5 \%$, respectively; and the corresponding rates of angina relief were $94.5 \%, 88.5 \%$, and $82.9 \%$, respectively. In the present study, no perioperative death occurred, angina was relieved in all patients, and no case exhibited any major complication. Despite the small number of patients in the reconstruction group, these results strongly suggest, to some extent, that this method could be safe and effective to achieve complete revascularization, but prospective trials are necessary to reach firm conclusions.

Reconstruction of LAD with diffuse stenosis can be achieved by two methods. The first method is to widen and reconstruct LAD using a LIMA patch. The second method is to widen and reconstruct the target artery with a GSV patch and then establish an end-toside anastomosis between the LIMA graft and the venous patch. The former is more frequently adopted and can deliver satisfactory results ${ }^{[11]}$. In the reconstruction group, 18 patients underwent LAD reconstruction with LIMA patch and four with SVG patch. The arteries were patent during the follow-up period. There are three technical points that are essential for widening the target arteries. First, incisions in the target arteries should extend beyond the boundaries of the stenoses and the anastomotic stomas should reach normal coronary arteries. This could, in theory, substantially decrease the incidence of intimal hyperplasia. The second point is to make sure that the collateral vessel openings are located within the lumen during suture, which can effectively improve target artery perfusion. The third point is to isolate the atherosclerotic plaques from the lumen after angioplasty. As the rupture of atherosclerotic plaques with thin and weak fibrous caps is the major cause of thrombosis, unstable angina and Ml, keeping these atherosclerotic plaques out of the reconstructed coronary artery lumen can lower the rates of perioperative $\mathrm{Ml}$ and postoperative long-term cardiac events.

The method of coronary artery reconstruction and surgical patch angioplasty of the coronary artery for treatment of diffuse $C A D$ requires a long duration of surgery, leading to prolonged periods of CPB and aortic cross-clamping. Existing myocardial protection techniques can meet the requirements of complex and long surgical procedures and will not increase the risk of surgery. One possibility is the use of one-off infusion of HTK solution, which can provide protection for over 2 hours ${ }^{[24]}$. This is longer than the duration of myocardial ischemia of patients in the reconstruction group, at $73 \pm 21$ minutes. During operation, the low temperature and cooling of the heart surface can lengthen to some extent the safe duration of myocardial ischemia. Due to the good results of reconstruction, satisfactory blood flows in grafts were achieved, thus lowering the risks of postoperative $\mathrm{Ml}$ and low cardiac output ${ }^{[25]}$ and increasing the patency rates of the arteries. Among the patients in the reconstruction group, perioperative $\mathrm{Ml}$ and low cardiac output were not observed, and the short- to medium-term patency rates were satisfactory.
The present study has limitations. The main limitation of the study is that it compared two different surgeries performed for two different indications/diseases. This is because it would be unethical to perform standard CABG in patients with diffuse CAD. In addition, the sample size was small, and all patients were from a single center. In addition, the follow-up was short.

\section{CONCLUSION}

In conclusion, for patients with long-segment or multiple diffuse coronary artery stenoses, performing coronary artery reconstruction and bypass grafting with LIMA or SVG patch through incisions on stenoses does not seem to pose additional surgical risk and achieved short-term results that could be comparable to standard CABG performed in patients with "regular" (non-diffuse) CAD. Given the novelty and immaturity of this technique, further research is needed to investigate the long-term graft patency rate, incidence of cardiac events, and other relevant issues.

\section{No financial support. \\ No conflict of interest.}

\section{Authors' roles \& responsibilities}

DL Substantial contributions to the conception or design of the work; or the acquisition, analysis or interpretation of data for the work; drafting the work or revising it critically for important intellectual content; final approval of the version to be published

PG

Substantial contributions to the conception or design of the work; or the acquisition, analysis or interpretation of data for the work; final approval of the version to be published

LC Substantial contributions to the conception or design of the work; or the acquisition, analysis or interpretation of data for the work; final approval of the version to be published

YW Substantial contributions to the conception or design of the work; or the acquisition, analysis or interpretation of data for the work; final approval of the version to be published

GW Substantial contributions to the conception or design of the work; or the acquisition, analysis or interpretation of data for the work; final approval of the version to be published

CX Substantial contributions to the conception or design of the work; or the acquisition, analysis or interpretation of data for the work; drafting the work or revising it critically for important intellectual content; final approval of the version to be published 


\section{REFERENCES}

1. Brown RA, Shantsila E, Varma C, Lip GY. Epidemiology and pathogenesis of diffuse obstructive coronary artery disease: the role of arterial stiffness, shear stress, monocyte subsets and circulating microparticles. Ann Med. 2016; 48(6):444-55. doi:10.1080/07853890.2016.1190861.

2. Levine GN, Bates ER, Blankenship JC, Bailey SR, Bittl JA, Cercek B, et al. 2011 ACCF/AHA/SCAl guideline for percutaneous coronary intervention: a report of the American college of cardiology foundation/American heart association task force on practice guidelines and the society for cardiovascular angiography and interventions. Circulation. 2011;124(23):e574-651. Erratum in: Circulation. 2012;125(8):e412. Dosage error in article text. doi:10.1161/ CIR.0b013e31823ba622.

3. Falk E, Shah PK, Fuster V. Coronary plaque disruption. Circulation. 1995;92(3):657-71. doi:10.1161/01.cir.92.3.657.

4. Farb A, Tang AL, Burke AP, Sessums L, Liang Y,Virmani R. Sudden coronary death. Frequency of active coronary lesions, inactive coronary lesions, and myocardial infarction. Circulation. 1995;92(7):1701-9. doi:10.1161/01.cir.92.7.1701.

5. Libby P. Molecular bases of the acute coronary syndromes. Circulation. 1995;91(11):2844-50. doi:10.1161/01.cir.91.11.2844.

6. Mannheimer C, Camici P, Chester MR, Collins A, DeJongste M, Eliasson T, et al. The problem of chronic refractory angina; report from the ESC joint study group on the treatment of refractory angina. Eur Heart J.2002;23(5):355-70. doi:10.1053/euhj.2001.2706.

7. Lenzen M, Scholte op Reimer W, Norekvål TM, De Geest S, Fridlund B, Heikkilä J, et al. Pharmacological treatment and perceived health status during 1-year follow up in patients diagnosed with coronary artery disease, but ineligible for revascularization. Results from the Euro heart survey on coronary revascularization. Eur J Cardiovasc Nurs. 2006;5(2):115-21. doi:10.1016/j.ejcnurse.2006.01.003.

8. Williams B, Menon M, Satran D, Hayward D, Hodges JS, Burke MN, et al. Patients with coronary artery disease not amenable to traditional revascularization: prevalence and 3-year mortality. Catheter Cardiovasc Interv. 2010;75(6):886-91. doi:10.1002/ccd.22431.

9. Kandzari DE, Lam LC, Eisenstein EL, Clapp-Channing N, Fine JT, Califf RM, et al. Advanced coronary artery disease: appropriate end points for trials of novel therapies. Am Heart J. 2001;142(5):843-51. doi:10.1067/mhj.2001.119136.

10. Lozano I, Capin E, de la Hera JM, Llosa JC, Carro A, Lopez-Palop R. Diffuse coronary artery disease not amenable to revascularization: long-term prognosis. Rev Esp Cardiol (Engl Ed). 2015;68(7):631-3. doi:10.1016/j. rec.2015.02.013.

11. Fukui T, Tabata M, Taguri M, Manabe S, Morita S, Takanashi S. Extensive reconstruction of the left anterior descending coronary artery with an internal thoracic artery graft. Ann Thorac Surg. 2011;91(2):445-51. doi:10.1016/j.athoracsur.2010.10.002.

12. Graham MM, Chambers RJ, Davies RF. Angiographic quantification of diffuse coronary artery disease: reliability and prognostic value for bypass operations. J Thorac Cardiovasc Surg. 1999;118(4):618-27. doi:10.1016/ S0022-5223(99)70006-1.
13. Kirali K, Ozen Y. Surgical treatment in diffuse coronary artery disease. In: Kirali K (ed) Coronary Artery Disease: Assessment, Surgery, Prevention. IntechOpen. 2015.

14. Prabhu AD, Thazhkuni IE, Rajendran S, Thamaran RA, Vellachamy KA, Vettath MP. Mammary artery patch reconstruction of left anterior descending coronary artery. Asian Cardiovasc Thorac Ann. 2008;16(4):313-7. doi:10.1177/021849230801600412.

15. Harling L, Sepehripour AH, Ashrafian H, Lane T, Jarral O, Chikwe J, et al. Surgical patch angioplasty of the left main coronary artery. Eur J Cardiothorac Surg. 2012;42(4):719-27. doi:10.1093/ejcts/ezs324.

16. Lampropoulos K, Kavouras C, Charitos C. Left main reconstruction as an alternative method to $\mathrm{CABG}$ after primary $\mathrm{PCl}$ complication. Indian Heart J. 2015;67(3):259-61. doi:10.1016/j.ihj.2015.03.018.

17. Thistlethwaite PA, Madani MM, Kriett JM, Milhoan K, Jamieson SW. Surgical management of congenital obstruction of the left main coronary artery with supravalvular aortic stenosis. JThorac Cardiovasc Surg. 2000;120(6):1040-6. doi:10.1067/mtc.2000.110493.

18. Ngaage DL, Hashmi I, Griffin S, Cowen ME, Cale AR, Guvendik L. To graft or not to graft? Do coronary artery characteristics influence early outcomes of coronary artery bypass surgery? Analysis of coronary anastomoses of 5171 patients. J Thorac Cardiovasc Surg. 2010;140(1):66-72, 72.e1. doi:10.1016/j. jtcvs.2009.09.029.

19. Ostrom MP, Gopal A, Ahmadi N, Nasir K, Yang E, Kakadiaris I, et al. Mortality incidence and the severity of coronary atherosclerosis assessed by computed tomography angiography. J Am Coll Cardiol. 2008;52(16):133543. doi:10.1016/j.jacc.2008.07.027.

20. Xiao C, Yang M, Liu G, Gao C. Reconstruction and revascularization for diffuse coronary artery disease by repair with a patch across the stenosis: report of 26 cases. Military Med Res. 2014;214(5):396-400.

21. Rocha AS, Dassa NP, Pittella FJ, Barbosa ON, Brito JO, Tura B, et al. High mortality associated with precluded coronary artery bypass surgery caused by severe distal coronary artery disease. Circulation. 2005;112(9 Suppl):I328-31. doi:10.1161/CIRCULATIONAHA.104.525717.

22. Barra JA, Bezon E, Mondine P, Resk A, Gilard M, Mansourati J, et al. Surgical angioplasty with exclusion of atheromatous plaques in case of diffuse disease of the left anterior descending artery: 2 years' follow-up. Eur J Cardiothorac Surg. 2000;17(5):509-14. doi:10.1016/s1010-7940(00)00403-6.

23. Ogus TN, Basaran M, Selimoglu O, Yildirim T, Ogus H, Ozcan H, et al. Longterm results of the left anterior descending coronary artery reconstruction with left internal thoracic artery. Ann Thorac Surg. 2007:83(2):496-501. doi:10.1016/j.athoracsur.2006.09.073.

24. Savini C, Camurri N, Castelli A, Dell'Amore A, Pacini D, Suarez SM, et al. Myocardial protection using HTK solution in minimally invasive mitral valve surgery. Heart Surg Forum. 2005;8(1):E25-7. doi:10.1532/HSF98.20041145.

25. Soylu E, Harling L, Ashrafian H, Athanasiou T. Does coronary endarterectomy technique affect surgical outcome when combined with coronary artery bypass grafting? Interact Cardiovasc Thorac Surg. 2014;19(5):848-55. doi:10.1093/icvts/ivu261. 